\title{
Um estudo do impacto de egressos no desenvolvimento regional como reflexo da interiorização do Ensino Superior
}

\author{
Helen Ferreira, Edgar Oliveira, Reinaldo Braga, Mauro Oliveira, Carina Oliveira
}

\author{
${ }^{1}$ Laboratório de Redes de Computadores e Sistemas (LAR) \\ Instituto Federal de Educação, Ciência e Tecnologia do Ceará (IFCE)
}

\begin{abstract}
This paper discusses the in loco impacts of the performance of graduates of Brazilian Higher Educational Institutions (HEI) located outside large urban centers, taking as a case study the Computer Science course at the Federal Institute of Ceará (IFCE) Campus Aracati. It outlines the profile of graduates from the crossing of several indicators: type and place of professional activity, salary range, postgraduate and extracurricular training during graduation. It is shown that, despite the majority of graduates working in the area of technology with good salaries, there was a considerable exodus of graduates from the city of formation and region to the capital Fortaleza-CE, which calls into question the need for new and urgente strategies for socioeconomic development in country towns that are home to HEI.
\end{abstract}

Resumo. Este trabalho discute os impactos in loco da atuação de egressos de Instituições de Ensino Superior (IES) brasileiras localizadas fora de grandes centros urbanos, tendo como estudo de caso o curso de Ciência da Computação do Instituto Federal do Ceará (IFCE) Campus Aracati. Nele é delineado o perfil dos egressos a partir do cruzamento de diversos indicadores: tipo e local de atuação profissional, faixa salarial, pós-graduação e formação extracurricular durante a graduação. É mostrado que, apesar da maioria dos egressos atuar na área de tecnologia com bons salários, houve um êxodo considerável dos egressos oriundos do município de formação e região para a capital Fortaleza$C E$, o que coloca em questão a necessidade de novas e urgentes estratégias para desenvolvimento socioeconômico das regiões interioranas que abrigam IES.

\section{Introdução}

A importância da interiorização e democratização da educação superior tem sido tema recorrente nas últimas décadas, gerando desde inúmeros trabalhos e debates acadêmicos a ambiciosos planos de governo. No entanto, ressalta-se que ao se analisar a expansão da educação superior no interior do Brasil, não basta considerar somente o crescimento acelerado do número de Instituições de Ensino Superior (IES), nem tampouco o aumento do número de matrículas e a ampliação de cursos. Faz-se necessário também um estudo sobre os impactos econômicos, sociais e culturais dessas instituições em seus lócus, o que inclui, impreterivelmente, os efeitos da atuação profissional dos egressos dessas IES nos municípios de formação, especialmente das IES localizadas nos pequenos e médios municípios brasileiros. O estudo do "futuro prometido do lado de fora" aos egressos das IES localizadas no interior do Brasil não tem despertado a contento a atenção dos teóricos e praticistas do cenário educacional brasileiro. 
Como contribuição nessa direção, o presente trabalho apresenta um minucioso estudo de caso sobre a relação dos egressos de uma IES da área de Tecnologia da Informação e Comunicação (TIC) e seu habitat inicial (i.e, o município de formação e/ou o município de origem). Destaca-se que, apesar da análise ter sido realizada em uma pequena parcela do aspecto amostral, ela serve como reflexão ao grave problema da apatia que assola uma grande parcela das IES localizadas no interior do Brasil quando o tema é o "the day after" na vida do egresso, bem como a falta de oportunidades para a sua realização profissional e pessoal no próprio município. Em grande parte, o resultado é o êxodo dos egressos para grandes centros urbanos (seja no país ou no exterior) ou a procura por um subemprego em setores alheios à sua formação. No primeiro caso, a inexistência de oportunidades locais é a mola propulsora para o que tem se configurado como fuga de talentos do seu município de formação e/ou município de origem. No segundo caso, é catastrófico se observar o desperdício de tempo do próprio jovem e de recursos empregados pela sociedade em uma formação que não será utilizada.

No mais, os dois casos direcionam-se na contramão das políticas públicas de democratização do acesso à educação superior no Brasil [Brasil 2014], já que uma das grandes finalidades da interiorização das IES é a fixação de capital humano de alto nível no município de formação e região para geração de externalidades positivas. No caso de cursos na área de TIC, pode-se citar como exemplos de externalidades positivas a geração de produtos/processos/serviços inovadores; estabelecimento de novas empresas, startups e/ou parques tecnológicos; a atração de investimentos de alto impacto tecnológico capazes de dinamizar arranjos produtivos, sociais e culturais locais; etc.

Neste contexto, a motivação inicial para a realização do estudo de caso do presente trabalho surgiu após a observação de professores do curso de Bacharelado em Ciência da Computação do Instituto Federal de Educação, Ciência e Tecnologia do Ceará (IFCE) Campus Aracati quanto aos desafios enfrentados por muitos egressos em conseguir colocação profissional na área de TIC no município de formação e região. No mais, também surgiu o questionamento de qual foi o real impacto das formações extracurriculares recebidas pelo egresso durante a graduação (Monitoria, Pesquisa, Desenvolvimento e Extensão) na sua atuação profissional (no mercado e na academia).

Dentre os vários resultados apresentados, é mostrado que um grande número de egressos procurou outros municípios (principalmente a capital Fortaleza-CE) onde o seu aprendizado caro, em tempo e recursos, foi capaz de gerar uma melhor colocação profissional e uma maior renda e, portanto, os fez encontrar o "futuro prometido do lado de fora". No final, o trabalho apresenta considerações sobre estratégias que podem ser adotadas pelas IES para incentivar a cultura de inovação tecnológica e o espírito empreendedor de estudantes no interior do país.

\section{Trabalhos Relacionados}

Nesta seção, são apresentados trabalhos recentes que analisam o perfil de egressos de cursos de TIC de IES localizadas fora dos grandes centros urbanos e que abordam assuntos como inserção no mercado de trabalho, município de atuação e pós-graduação.

O trabalho de [Nunes et al. 2020] tem como objetivo delinear o perfil de egressos de três cursos de TIC de duas IES públicas do interior da Amazônia (Universidade Federal do Pará - UFPA e Universidade Federal do Oeste do Pará - UFOPA) considerando 
temáticas como ocupação e formação acadêmica. Os dados dos egressos foram coletados por meio de um formulário enviado via e-mail. $\mathrm{O}$ formulário foi respondido por 55 egressos (20\% do total). Os resultados mostram que muitos egressos atuam na área de TIC e que alguns realizaram uma pós-graduação. Porém, o artigo não apresenta informações sobre a remuneração e município de atuação dos egressos, além de não informar se os egressos realizaram pós-graduação na área.

Em [Finger et al. 2020], um formulário enviado via e-mail foi utilizado para coletar dados de egressas dos cursos de Ciência da Computação (CC) e Engenharia de Software (ES) da Universidade Federal do Pampa (UNIPAMPA). A pesquisa foi respondida por 16 egressas (64\% do total), sendo 11 do curso de CC e 5 do curso de ES. A maioria das egressas teve experiências na área de formação, mas o artigo não cita o município de atuação, apesar de informar que 6 egressas residem na capital do estado, 4 continuam no município de formação e as demais migraram para outros estados. O trabalho aponta que as egressas do curso de $\mathrm{CC}$ tendem a recebem remunerações mais elevadas que as do curso de ES. Também é apontado que, durante a graduação, 10 egressas atuaram como bolsistas de projetos de Ensino, Pesquisa, Extensão ou Gestão, sendo estas as que mais buscaram uma pós-graduação na área de TIC.

O trabalho [Silva et al. 2019] utiliza os resultados de um formulário online para delinear a trajetória acadêmica e o perfil profissional de egressas de dois cursos de TIC da Universidade Federal da Paraíba (UFPB) Campus IV, distante cerca de $67 \mathrm{~km}$ da capital João Pessoa. A amostra da pesquisa alcançou 27 egressas (58,7\% do total). Um ponto positivo do trabalho é que apresenta em detalhes a relação entre a atuação profissional e o município de atuação das egressas. No caso, a maioria das egressas que atua profissionalmente na área de TIC reside na capital (29,64\%); a maioria que cursa pós-graduação também reside na capital $(7,42 \%)$ ou na cidade de São Paulo-SP $(7,42 \%)$; e a maioria que não atua profissionalmente reside no município de formação e região $(7,4 \%)$.

\section{Estudo de Caso}

\subsection{Contextualização}

O objetivo do estudo de caso é delinear o perfil dos egressos do curso de Bacharelado em Ciência da Computação (BCC) do Instituto Federal de Educação, Ciência e Tecnologia do Ceará (IFCE) Campus Aracati no contexto das seguintes temáticas principais: inserção no mercado de trabalho, faixa salarial, mobilidade e impacto da formação extracurricular durante a graduação na vida profissional e acadêmica.

O município de Aracati-CE fica a cerca de 149 km da capital Fortaleza-CE. Segundo o Instituto Brasileiro de Geografia e Estatística (IBGE), em 2010, a população do município girava em torno de 69.159 mil habitantes, com população estimada de 74.975 mil habitantes em 2020 [IBGE 2021]. Dados de 2010, também apontam um Índice de Desenvolvimento Humano Municipal (IDHM) ${ }^{1}$ de 0,655. Segundo dados do IBGE de 2018, o Produto Interno Bruto (PIB) per capita é de $\mathrm{R} \$ 15.210,71$ e o salário médio mensal dos trabalhadores formais em Aracati é de 1,7 salários mínimos.

O curso de BCC do IFCE Campus Aracati iniciou suas atividades em 2012. As

\footnotetext{
${ }^{1} \mathrm{O}$ IDHM é uma medida composta por três dimensões do desenvolvimento humano: educação, longevidade e renda. $\mathrm{O}$ índice varia de 0 a 1 . Quanto mais próximo de 1, maior o desenvolvimento humano.
} 
formas de ingresso ao curso são: via processo seletivo público pelo Sistema de Seleção Unificado (SiSU), como aluno especial, graduado ou transferido. O curso tem duração de 4 anos com oferta semestral, com turnos vespertino e noturno intercalados a cada semestre. O curso é reconhecido pelo MEC com conceito nota 3. Até a data de publicação deste trabalho, o curso formou 44 estudantes, sendo 35 homens e 9 mulheres.

\subsection{Metodologia}

A pesquisa realizada é de abordagem quantitativa e qualitativa. Foi elaborado um formulário com questões objetivas e subjetivas na ferramenta Google Forms para coleta de dados dos egressos. O link para o formulário foi enviado para o grupo de egressos reunidos virtualmente em um aplicativo de mensagem. Apesar de ter sido aplicado de forma remota, os autores do trabalho prestaram toda a assistência necessária aos egressos para as possíveis dúvidas quanto ao formulário, evitando assim equívocos na interpretação das questões e, consequentemente, evitando erros na tabulação dos dados.

Em seguida, foi realizada a tabulação dos dados e construção das visualizações. A ferramenta Google Sheets foi usada para gráficos e as ferramentas Google Maps e Leaflet (com plugins leafleat-swoopy e leafleat-heatmap) para as visualizações espaciais. Os resultados mais relevantes construídos através dessas ferramentas são apresentados e discutidos na próxima seção.

\subsection{Resultados e Discussões}

Dentre os 44 egressos do curso em análise, 39 responderam ao formulário (90\% do total), sendo 31 do sexo masculino e 8 do sexo feminino.

\subsubsection{Inserção dos egressos no mercado de trabalho}

Dentre os 39 egressos que responderam o formulário, 28 informaram que estão inseridos no mercado de trabalho $\mathrm{Na}$ Área de formação (71,8\%), 4 estão inseridos no mercado de trabalho Fora da Área de formação (10,25\%), 4 responderam que não estão atuando no mercado de trabalho por estarem cursando um mestrado em tempo integral $(10,25 \%)$ e, por fim, 3 afirmaram não estar trabalhando $(7,7 \%)$.

$\mathrm{O}$ cargo mais preenchido pelos egressos que atuam $\mathrm{Na}$ Área foi o de Analista de Sistemas/Desenvolvedor, com $75 \%$ das ocupações. O restante dos cargos se dividem entre Professor de Informática (7,1\%), Técnico em TI (7,1\%), Analista de Testes $(3,6 \%)$, Analista de Dados $(3,6 \%)$ e Gerente de Projeto (3,6\%). Já do lado dos egressos que atuam Fora da Área, os cargos ocupados são de Técnico em Eventos, Agente Estadual Agropecuário, Auxiliar Administrativo e Professor. No entanto, como será mostrado na sequencia deste trabalho, dentre os 4 egressos que atuam Fora da Área, 1 está cursando um Mestrado Acadêmico em Ciência da Computação e 1 já é Mestre em Ciência da Computação e atua de forma voluntária como pesquisador do IFCE Campus Aracati. Portanto, apesar desses dois egressos possuírem fonte de renda atuando Fora da Área, eles ainda possuem um vínculo com a área de computação e pretendem, em oportunidades futuras, migrar para empregos mais atrativos na computação.

Em relação aos egressos inseridos no mercado de trabalho, a Tabela 1 apresenta um comparativo entre os 28 egressos que atuam $\mathrm{Na}$ Área e os 4 que atuam Fora da Área, 
Tabela 1. Faixa salarial dos egressos que atuam no mercado de trabalho.

\begin{tabular}{|c|c|c|c|c|c|c|}
\hline \multirow[t]{2}{*}{ Atuação } & \multirow{2}{*}{ Vínculo } & \multicolumn{5}{|c|}{ Faixa Salarial (R\$) } \\
\hline & & $<1.500$ & $\begin{array}{ll}1.501 & a \\
2.500 & \end{array}$ & $\begin{array}{ll}2.501 & a \\
3.500 & \end{array}$ & $>5.000$ & $\begin{array}{l}\text { Não In- } \\
\text { formado }\end{array}$ \\
\hline \multirow{3}{*}{$\begin{array}{l}\text { Na Área } \\
\text { (28) }\end{array}$} & Contrato CLT (23) & 1 & 5 & 12 & 2 & 3 \\
\hline & Servidor Público (4) & 2 & - & - & 1 & 1 \\
\hline & Autônomo (1) & - & - & - & - & 1 \\
\hline \multirow{3}{*}{$\begin{array}{l}\text { Fora da } \\
\text { Área (4) }\end{array}$} & Contrato CLT (1) & - & - & - & - & 1 \\
\hline & Servidor Público (3) & 1 & - & 1 & - & 1 \\
\hline & Autônomo (0) & - & - & - & - & - \\
\hline
\end{tabular}

com destaque para o tipo de vínculo e a faixa salarial.

Sobre o tipo de vínculo de contratação do egresso, foi disponibilizado no formulário um conjunto de opções (ex: Contrato em regime de trabalho gerenciado pela Consolidação das Leis do Trabalho - CLT, Servidor Público, Autônomo, Processo Seletivo Temporário, etc). A Tabela 1 mostra somente as opções marcadas pelos egressos. Como podemos perceber pela tabela, dentre os 28 egressos que atuam $\mathrm{Na}$ Área, 23 possuem Contrato CLT (82,2\%), 4 são servidores públicos $(14,2 \%)$, enquanto 1 está trabalhando de forma autônoma (3,6\%). Já para os egressos que atuam Fora da Área, 3 são Servidores Públicos (75\%) e 1 possui Contrato CLT (25\%).

Em se tratando da faixa de remuneração, a Tabela 1 mostra a diferença entre a faixa salarial dos egressos que atuam $\mathrm{Na}$ Área e Fora da Área. No formulário aplicado, foram apresentadas faixas salariais, assim como a opção de não informar a faixa salarial. Um total de 7 egressos optou por não informar a faixa salarial. Não houve resposta para a faixa salarial de $R \$ 3.501$ a $R \$ 5.000 \mathrm{e}$, por isso, essa faixa não aparece na tabela. No caso dos egressos que atuam $\mathrm{Na}$ Área e informaram seus rendimentos, nota-se que a maioria (12 dos 28 egressos) está ganhando na faixa $R \$ 2.501$ a $R \$ 3.500$. Como será mostrado na Seção 3.3.2, a maioria desses egressos trabalha fora do município de Aracati e região. Ainda no perfil dos egressos atuando $\mathrm{Na}$ Área, observa-se que 3 deles possuem um salário acima de $R \$ 5.000$. Nesse caso, é importante destacar que apenas 1 atua em Aracati.

As principais conclusões da Seção 3.3.1 são:

- A maioria dos egressos atua no mercado de trabalho na área de formação com vínculo do tipo Contrato CLT e um salário acima de R 2.500 .

- A maioria dos egressos fora do mercado de trabalho se dedica integralmente a um Mestrado na área.

\subsubsection{Mobilidade dos egressos}

Nesta seção, são apresentados os resultados da análise da mobilidade dos egressos desde o município de Origem (i.e., o município onde residia antes de ingressar no curso) até o município de Destino (i.e., o município que reside atualmente, após a conclusão do curso). Os resultados dessa seção são apresentados em formato de tabela e complementados com a ajuda de mapas coropléticos. A tabela e os mapas consideram os dados dos egressos que atuam no mercado de trabalho.

A Tabela 2 apresenta a relação entre a atuação dos egressos que atuam no mercado 
Tabela 2. Origem e Destino dos egressos que atuam no mercado de trabalho.

\begin{tabular}{|c|c|c|c|c|}
\hline \multirow{2}{*}{ Atuação } & \multirow[b]{2}{*}{ Região/Estado } & \multirow[b]{2}{*}{ Município } & \multicolumn{2}{|c|}{ Qte de Egressos } \\
\hline & & & Origem & Destino \\
\hline \multirow{10}{*}{ Na Área (28) } & \multirow{5}{*}{ Litoral Leste/CE } & Aracati & 16 & 11 \\
\hline & & Icapuí & 3 & 1 \\
\hline & & Jaguaruana & 2 & - \\
\hline & & Beberibe & 1 & - \\
\hline & & Itaiçaba & 1 & - \\
\hline & Vale do Jaguaribe/CE & Morada Nova & 1 & - \\
\hline & \multirow{3}{*}{ Grande Fortaleza/CE } & Fortaleza & 2 & 14 \\
\hline & & Cascavel & 1 & - \\
\hline & & Eusébio & - & 1 \\
\hline & Agreste Setentrional/PE & Surubim & 1 & 1 \\
\hline \multirow{4}{*}{ Fora da Área (4) } & Litoral Leste/CE & Aracati & 2 & 2 \\
\hline & \multirow{2}{*}{ Vale do Jaguaribe/CE } & Morada Nova & 1 & 1 \\
\hline & & Limoeiro do Norte & 1 & - \\
\hline & Sertão do Canindé/CE & Canindé & - & 1 \\
\hline
\end{tabular}

de trabalho (Na Área e Fora da Área) e a localidade (Região/Estado e Município) dos egressos antes (Origem) e depois (Destino) da graduação no curso em análise. A tabela apresenta as regiões onde há pelo menos um registro de origem ou destino de egresso. Para a análise na sequência, é importante notar que o município de Aracati-CE, onde o campus do curso em análise está localizado, pertence à região chamada Litoral Leste.

Através dos dados da Tabela 2, pode-se perceber, inicialmente, que a maioria dos egressos que hoje atua no mercado de trabalho tinha como Origem o próprio município de Aracati (18 egressos, sendo $16 \mathrm{Na}$ Área e 2 Fora da Área) ou outro município do Litoral Leste (7 egressos $\mathrm{Na}$ Área). Além disso, percebe-se que o curso também atraiu pessoas de duas regiões próximas ao Litoral Leste: Vale do Jaguaribe (3 egressos, sendo $1 \mathrm{Na}$ Área e 2 Fora da Área) e Grande Fortaleza (3 egressos Na Área). Também atraiu um egresso de outro estado, Pernambuco (1 egresso Na Área). A opção de seleção via SiSU permitiu essa mobilidade dos estudantes entre regiões e estados. Aracati é colocado em destaque na Tabela 2 por ser o município com maior número de pessoas na Origem.

O formulário aplicado também revelou que durante a graduação 9 dos 14 egressos com Origem diferente de Aracati estabeleceram residência no município para a realização de seus estudos.

Visando uma melhor representação da extensão geográfica do atendimento do curso à comunidade, a Figura 1(a) ilustra uma representação espacial dos municípios em questão, com exceção de Surubim (com 1 egresso), que não foi representado no mapa para facilitar a visão em Aracati e região. Nesse mapa coroplético, as áreas com cores mais claras simbolizam uma menor densidade e as cores mais escuras uma maior densidade. Aracati é a área com a cor mais escura no mapa da Figura 1(a) (vermelho escuro), já que, como dito anteriormente, concentra a maior quantidade de egressos na Origem. Essa primeira análise confirma a importância da intervenção de uma instituição pública de qualidade na oferta de formação profissional no interior do país.

A coluna Destino da Tabela 2 mostra a quantidade de egressos por município após a conclusão do curso. Assim, ao se realizar uma comparação dos valores das colunas 


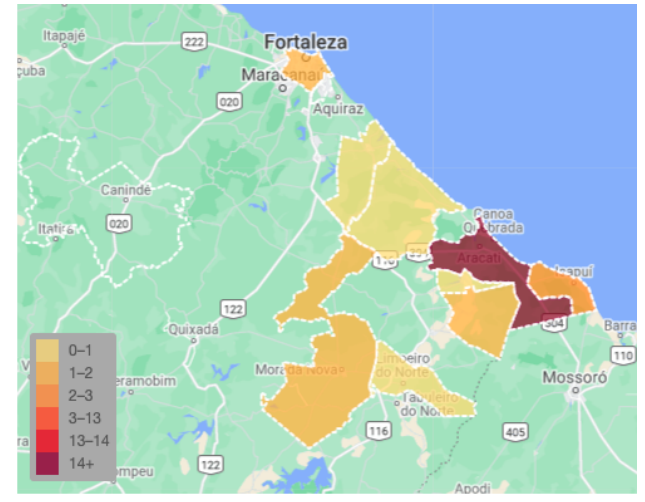

(a) Municípios de Origem.

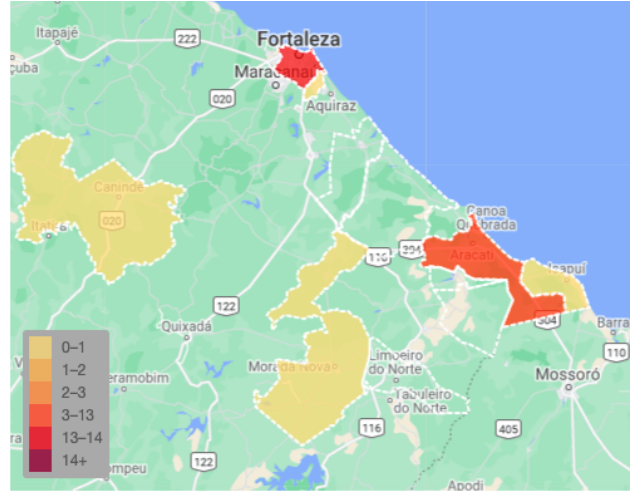

(b) Municípios de Destino.

Figura 1. Mapas Coropléticos antes e depois da graduação.

Origem e Destino, é possível obter uma visão macro da mobilidade dos egressos após a conclusão do curso. No caso dos egressos que atuam $\mathrm{Na}$ Área, a primeira conclusão relevante é de que, antes do curso, haviam 23 pessoas morando na região do Litoral Leste e que, após a conclusão de curso, esse número caiu drasticamente para 12. Destaca-se que Aracati, que concentrava o maior número de egressos na Origem, teve uma queda de 16 para 11. Já Fortaleza, que na Origem contava com apenas 2 pessoas, passou para 14 no Destino. Fortaleza é colocada em destaque na tabela por ser o município com maior número de pessoas no Destino. Quando questionados sobre as razões de mudança do município de formação e região, a maioria justificou a ausência de oportunidades locais na área de TIC. Alguns egressos também citaram a busca por novas experiências.

Quanto aos egressos que atuam Fora da Área, percebe-se que Aracati e Morada Nova continuaram com o mesmo número de egressos, Limoeiro do Norte perdeu um egresso e Canindé ganhou.

Para complementar a análise da tabela, o mapa coroplético da Figura 1(b) mostra as áreas de Destino dos egressos. Ao se comparar os dois mapas, de imediato, nota-se no mapa de Destino a ausência de cores em diversos municípios próximo à Aracati e o clareamento da tonalidade vermelha em Aracati. Além disso, destaca-se o aumento significativo na tonalidade da cor na capital Fortaleza, para onde a maioria dos egressos migrou após a graduação para atuar profissionalmente.

Apesar dos resultados até então apresentados nesse seção terem como foco os egressos que atuam no mercado de trabalho, também é relevante pontuar sobre os egressos que fazem/fizeram Mestrado, com e sem dedicação exclusiva. Primeiro, 2 já são mestres e 12 são mestrandos. Segundo, todos realizam/realizaram mestrado na área de TIC, sendo 7 em um Mestrado Acadêmico em Ciência da Computação em Fortaleza-CE, 6 em um Mestrado Acadêmico em Ciência da Computação em Mossoró-RN e 1 em um Mestrado em Informática e Sistemas em Coimbra, Portugal. No contexto da mobilidade dos egressos, vale então ressaltar que todos os mestrandos e mestres realizam/realizaram a formação fora do município de Aracati e região, que não ofertam nenhum Mestrado em Ciência da Computação ou áreas afins.

Os resultados apresentados sobre a mobilidade dos egressos após a graduação são preocupantes do ponto de vista do que já foi apontado na introdução deste trabalho, ou 
seja, revelam que, de fato, há uma fuga de talentos de pequenos municípios para um grande centro urbano na busca por colocação profissional e/ou pós-graduação.

As principais conclusões da Seção 3.3.2 são:

- O curso atraiu mais egressos oriundos da região Litoral Leste, em especial do próprio município de Aracati.

- Após a graduação, a maioria dos egressos que hoje atua $\mathrm{Na}$ Área migrou do seu município de Origem para trabalhar na capital Fortaleza-CE.

- Todos os egressos que realizam/realizaram Mestrado precisaram realizar a formação em Fortaleza-CE ou em outro Estado.

\subsubsection{Formação extracurricular durante a graduação}

O objetivo dos resultados apresentados nessa seção é entender os impactos da formação extracurricular vivenciada pelo estudante durante a graduação na sua atuação profissional após a conclusão do curso. Os tipos de formação extracurricular considerados no formulário foram: Monitoria, Pesquisa (ex: projetos de programas de Iniciação Científica), Desenvolvimento (ex: projetos com empresas do setor industrial via convênio ou via EMBRAPII ${ }^{2}$ ) e Extensão (ex: projetos sociais e/ou de inclusão tecnológica). No formulário, era permitido ao egresso marcar um ou mais tipos de formação extracurricular.

Inicialmente, os resultados já revelaram um indicador muito positivo: 36 dos 39 egressos $(92,3 \%)$ participaram de pelo menos uma formação extracurricular durante a graduação. Mais especificamente, 11 egressos participaram de apenas um tipo de formação, 12 egressos de 2 tipos de formação, 11 egressos de 3 tipos de formação e 2 egressos de 4 tipos de formação. Em resumo, a maioria dos egressos pôde vivenciar dois ou mais tipos de formação extracurricular ao longo da graduação. No formulário, foi perguntado se o egresso participou dessas formações como bolsista ou voluntário. Dentre esses 36 egressos, 34 receberam bolsa(s) de estudo $(94,4 \%)$ durante toda ou parte da graduação para a realização dessas atividades extracurriculares.

Na Figura 2, os tipos de formação extracurricular são cruzados com outra informação relevante no contexto deste trabalho: a atuação profissional do egresso. Na figura são considerados todos que responderam o formulário (39 egressos), que foram então divididos em seis categorias principais: egressos que só Trabalham na Área (20 egressos), egressos que Trabalham na Área e também fazem/fizeram Mestrado ( 8 egressos), egressos dedicados Exclusivamente ao Mestrado (4 egressos), egressos que só Trabalham Fora da Área (2 egressos), egressos que Trabalham Fora da Área e também fazem/fizeram Mestrado (2 egressos) e egressos que Não Trabalham (3 egressos). O eixo y da figura apresenta a porcentagem de egressos em relação ao total de egressos de cada categoria.

A Figura 2 mostra que Pesquisa foi a formação extracurricular mais realizada pelos egressos, seguido por Desenvolvimento, Extensão e Monitoria, respectivamente. Verifica-se também que Pesquisa é a única formação presente em todas as categorias. No mais, nota-se que $100 \%$ dos egressos que fazem/fizeram mestrado participaram de projetos de Pesquisa. Já os egressos que não participaram de nenhuma formação extracurricular ao longo da graduação estão nas categorias Trabalha Fora da Área ou Não Trabalha.

\footnotetext{
${ }^{2}$ Empresa Brasileira de Pesquisa e Inovação Industrial (https://embrapii.org.br/)
} 


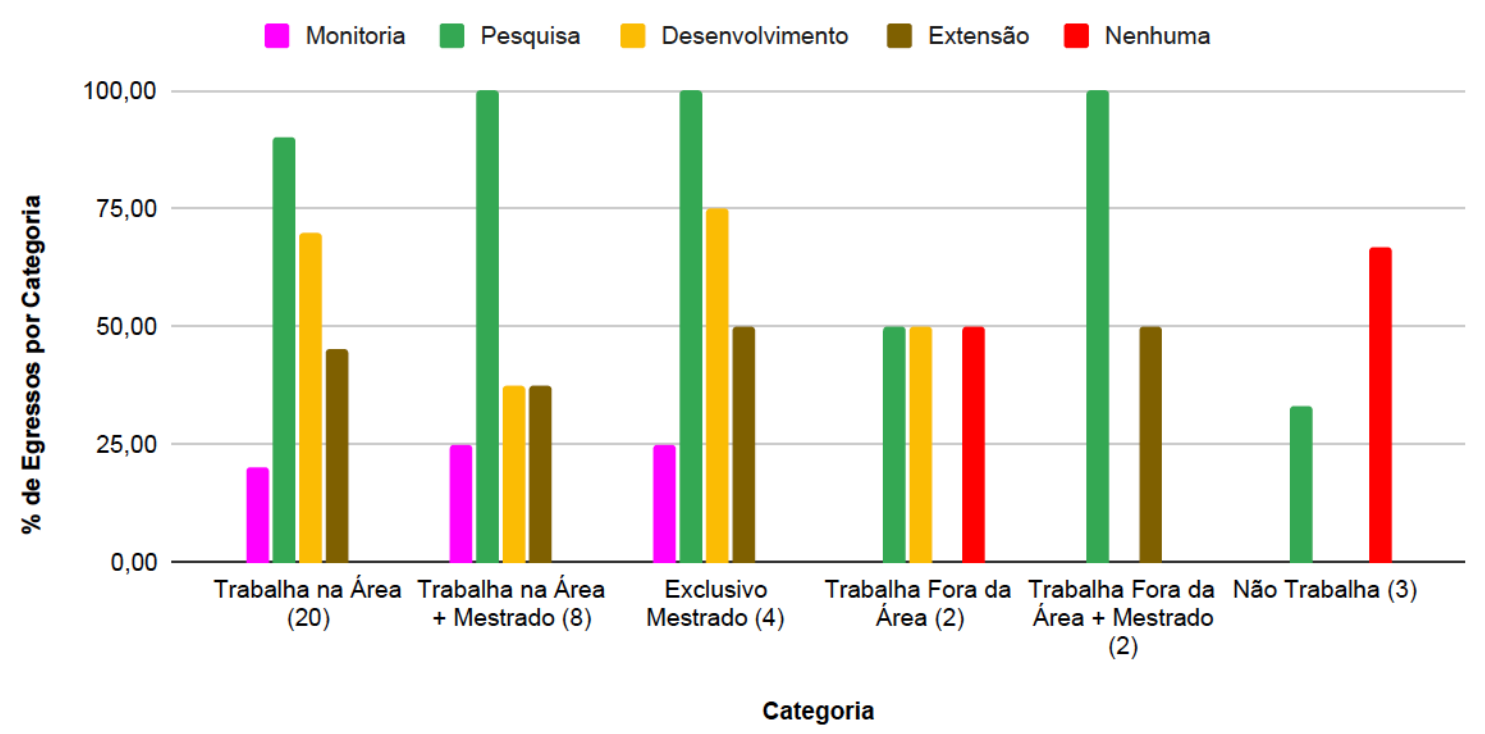

Figura 2. Tipos de formação extracurricular por atuação profissional do egresso.

É importante a consideração de que há um maior interesse por parte de uma instituição de educação de que um egresso de uma determinada área de formação de nível superior atue após a graduação dentro do contexto da sua área de formação e/ou esteja realizando qualificação em nível de pós-graduação também dentro da área. Nesse contexto, pode-se dizer que há três categorias "de maior interesse" como destino dos egressos em estudo: Trabalha na Área, Trabalha na Área + Mestrado e Exclusivo Mestrado. Na Figura 2, verifica-se que somente nessas categorias há participações de egressos nos quatro tipos de formações extracurriculares, com destaque para Pesquisa e Desenvolvimento. Logo, pode-se concluir que os egressos que hoje atuam na área (trabalhando e/ou estudando) puderam vivenciar experiências práticas ao longo da graduação que beneficiaram positivamente sua atuação profissional.

As principais conclusões da Seção 3.3.3 são:

- A maioria dos egressos participou de pelo menos um tipo de formação extracurricular ao longo da graduação.

- A maioria dos egressos que trabalha e/ou faz mestrado Na Área participou de múltiplas formações extracurriculares ao longo da graduação.

- Todos egressos que fazem/fizeram Mestrado participaram de projetos de Pesquisa ao longo da graduação.

- A maioria dos egressos que não trabalha não participou de nenhuma formação extracurricular durante a graduação.

\section{Considerações Finais}

Este trabalho apresentou uma análise sobre egressos de uma IES localizada em um município do interior do Brasil. Foram discutidos graves impactos provocados pelo êxodo dos egressos motivados, em geral, pela falta de oportunidade local para sua realização profissional. O trabalho apresentado faz uso de um estudo de caso do curso de Bacharelado em Ciência da Computação do IFCE Campus Aracati. A principal constatação deste estudo, dentre diversos aspectos abordados, é que a maioria dos egressos está hoje empregada na área de TIC, com bons salários. Porém, muitos tiveram, para tanto, que migrar 
para a capital. Concluiu-se no estudo de caso em pauta que a excelente formação dada pelo IFCE ajudou efetivamente a resolver o problema individual dos egressos no que se refere ao seu engajamento no mercado de trabalho. Por outro lado, em consequência do êxodo constatado pelo estudo, houve a penalização da sociedade local que perdeu, por falta de oportunidades locais compatíveis com a nova formação profissional dos egressos, diversos cidadãos intelectualmente mais preparados, capazes de apropriarem-se de seu entorno social para a melhoria do município em suas instâncias sociais, culturais, econômica e políticas.

Outrossim, advoga-se que é também dever de toda IES canalizar esforços que facilitem a criação de oportunidades profissionais no lócus de seus egressos para que eles, se assim o desejarem, possam ter a opção de trabalharem em seu "habitat residencial" e, assim, contribuírem para a melhoria anteriormente citada. Uma política institucional que aponta nessa direção acontece quando a própria IES incentiva, desde o primeiro dia de contato com o estudante, a cultura de inovação tecnológica, o espírito empreendedor de seus alunos e sua responsabilidade social. Neste contexto, é essencial, para fortalecer a vocação das IES, a defesa e a prática de conceitos modernos tendo o estudante como protagonista principal, tais como Ecossistemas de Inovação, Empreendedorismo Sustentável, Incubação de Empresas, Aceleração de Negócios, Economia Criativa, $M a$ kerspaces, criação de Parque Tecnológico local, Polo Tecnológico, Negócios de Impacto Social, etc. Criar ambientes e ações pedagógicas favoráveis à prática de tais conceitos não só ajuda uma IES a melhor cumprir seu papel, mas a torna indispensável como verdadeiro combustível da transformação social de uma comunidade "perdida nas brenhas", desmascarando estatísticas por vezes falaciosas que escamoteiam sua verdadeira missão.

\section{Referências}

Brasil (2014). Ministério da Educação. A Democratização e Expansão da Educação Superior no País 2003-2014. Brasília-DF.

Finger, A., Bordin, A., and de Mello, A. (2020). Perfil das Egressas dos Cursos de Computação da UNIPAMPA: Uma Análise da Formação Acadêmica e da Atuação Profissional. In Anais do XIV Women in Information Technology, Porto Alegre, RS, Brasil. SBC.

IBGE (2021). Instituto Brasileiro de Geografia e Estatística. Cidades e Estados: Aracati. Disponível em: https://www.ibge.gov.br/cidades-e-estados/ce/aracati.html. Último Acesso em: 13 de Abril de 2021.

Nunes, L. H., Reis, J., Paxiúba, C., Ponte, M., Nascimento, M., and Nascimento, R. (2020). Perfil dos Egressos de Computação do Interior da Amazônia no Mercado de Trabalho. In Anais do XIV Women in Information Technology, Porto Alegre, RS, Brasil. SBC.

Silva, J. D., Dantas, V., Figueiredo, R., Medeiros, S., and Costa, T. (2019). Perfil Profissional das Egressas dos Cursos de Computação da Universidade Federal da ParaíbaCampus IV. In Anais do XIII Women in Information Technology, Porto Alegre, RS, Brasil. SBC. 